OPEN ACCESS

Edited by:

Tongzhi Wu,

The University of Adelaide, Australia

Reviewed by:

Enzo Spisni,

University of Bologna, Italy

P. Trayhurn,

University of Liverpool,

United Kingdom

*Correspondence:

Damien J. Keating

damien.keating@flinders.edu.au

Specialty section:

This article was submitted to Clinical and Translational Physiology, a section of the journal

Frontiers in Physiology

Received: 08 January 2019

Accepted: 27 March 2019

Published: 16 April 2019

Citation:

Martin AM, Sun EW, Rogers GB and Keating DJ (2019) The Influence

of the Gut Microbiome on Host Metabolism Through the Regulation

of Gut Hormone Release.

Front. Physiol. 10:428.

doi: 10.3389/fphys.2019.00428

\section{The Influence of the Gut Microbiome on Host Metabolism Through the Regulation of Gut Hormone Release}

\author{
Alyce M. Martin', Emily W. Sun', Geraint B. Rogers2,3 and Damien J. Keating ${ }^{1,4 *}$ \\ ${ }^{1}$ Molecular and Cellular Physiology Laboratory, College of Medicine and Public Health, Flinders University, Adelaide, SA, \\ Australia, ${ }^{2}$ Microbiome Research Laboratory, Flinders University, Adelaide, SA, Australia, ${ }^{3}$ Infection and Immunity, South \\ Australian Health and Medical Research Institute, Adelaide, SA, Australia, ${ }^{4}$ Nutrition and Metabolism, South Australian \\ Health and Medical Research Institute, Adelaide, SA, Australia
}

The microbial community of the gut conveys significant benefits to host physiology. A clear relationship has now been established between gut bacteria and host metabolism in which microbial-mediated gut hormone release plays an important role. Within the gut lumen, bacteria produce a number of metabolites and contain structural components that act as signaling molecules to a number of cell types within the mucosa. Enteroendocrine cells within the mucosal lining of the gut synthesize and secrete a number of hormones including CCK, PYY, GLP-1, GIP, and 5-HT, which have regulatory roles in key metabolic processes such as insulin sensitivity, glucose tolerance, fat storage, and appetite. Release of these hormones can be influenced by the presence of bacteria and their metabolites within the gut and as such, microbialmediated gut hormone release is an important component of microbial regulation of host metabolism. Dietary or pharmacological interventions which alter the gut microbiome therefore pose as potential therapeutics for the treatment of human metabolic disorders. This review aims to describe the complex interaction between intestinal microbiota and their metabolites and gut enteroendocrine cells, and highlight how the gut microbiome can influence host metabolism through the regulation of gut hormone release.

Keywords: enteroendocrine cells, microbiome, metabolism, GLP-1, PYY, GIP, serotonin, CCK

\section{INTRODUCTION}

The gastrointestinal (GI) tract is host to a highly complex microbial ecosystem, comprising of bacteria, yeast, fungi, bacteriophages, and other viruses (Scarpellini et al., 2015), as well as protozoa and archaea (Koskinen et al., 2017; Laforest-Lapointe and Arrieta, 2018). Commensal bacteria, hereto referred to as gut microbiota, are found along the length of the GI tract and at greatest density within the caecum and colon, and along with their genes and gene products (collectively referred to as the gut microbiome), perform several functions that heavily influence host physiology. Not only does the gut microbiota play a critical role in modulating host immune defense (Belkaid and Hand, 2014) and brain function (Rogers et al., 2016), it also plays a role in regulating host 
metabolism (Turnbaugh et al., 2006; Turnbaugh and Gordon, 2009; Vrieze et al., 2012, 2014; Le Chatelier et al., 2013; Nieuwdorp et al., 2014; Blaut, 2015; Hartstra et al., 2015; Seeley et al., 2015; Suarez-Zamorano et al., 2015; Aguirre et al., 2016; Pedersen et al., 2016; Molinaro et al., 2017; Rodrigues et al., 2017; Brubaker, 2018; Fabbiano et al., 2018). This is well-illustrated by the transfer of microbiota from lean and obese human twins into germ-free (GF) mice lacking a native gut microbiome, resulting in the conveyance of the metabolic phenotype of the host (Ridaura et al., 2013). Microbiota depletion in mice confers significant protection against metabolic dysregulation induced by a high-fat diet such as obesity, glucose intolerance and insulin resistance (Suarez-Zamorano et al., 2015), all of which are hallmarks of metabolic diseases including type 2 diabetes (T2D). While bacteria-mediated inflammation is associated with detrimental metabolic effects in mice (Lam et al., 2012; Molinaro et al., 2017), the underlying mechanisms by which gut microbiota influence metabolism are still not fully understood. The gut microbiome contributes significantly to host energy harvest by converting inaccessible nutrient sources such as plant polysaccharides and other complex carbohydrates, into readily absorbable metabolites (Tremaroli and Backhed, 2012). Moreover, a key link has been established between the gut microbiome and the release of several gut hormones that are important regulators of peripheral metabolism.

Within the mucosal lining of the gut, specialized enteroendocrine (EE) cells synthesize and secrete several hormones that facilitate a range of key physiological processes. Collectively, EE cells constitute the largest endocrine organ in the body (Ahlman and Nilsson, 2001), despite making up less than $1 \%$ of the total epithelial cell population in the gut. A broad number of EE cell subpopulations have been defined, based largely on their hormone expression profile (Fothergill et al., 2017). EE cells have the capacity to sense the luminal nutrient environment of the gut and are differentially responsive to many dietary compounds and luminal conditions within the intestine. Mounting evidence has highlighted that the gut microbiome influences EE cell hormone release, with downstream consequences for host metabolism and metabolic disease progression (Figure 1). There is also recent evidence that microbial-mediated release of gut hormones may influence other EE cell types (Lund et al., 2018), demonstrating the complexity that is the relationship between the gut microbiome, gut hormone release, and host metabolism. This review aims to describe how intestinal microbiota and their metabolites can influence host metabolism through the regulation of gut hormone release.

\section{MICROBIAL METABOLITES SIGNAL WITH HOST CELLS}

\section{Short Chain Fatty Acids}

The gut microbiota produces an array of metabolites through the breakdown of indigestible carbohydrates (Figure 2). The most abundant of these metabolites are the short chain fatty acids (SCFAs) acetate, propionate and butyrate (Topping and
Clifton, 2001), which exist at a ratio of approximately 3:1:1 in the human intestinal lumen, respectively (Cummings et al., 1987; Mowat and Agace, 2014), however, this ratio is, at least in part, dependent upon both diet and microbial composition. The fate of these bacteria-derived SCFAs differs substantially: acetate is readily absorbed into the circulation for distribution to peripheral tissues. Propionate, on the hand, is metabolized by the liver upon absorption (Koh et al., 2016), while the majority of butyrate is consumed locally by colonocytes as their primary fuel source. While the majority of bacteria-derived SCFAs are present in the colon, lesser amounts have also been detected in the ileum of pigs, as a result of cecoileal reflux (Cuche and Malbert, 1999), and to a lesser extent, the proximal small intestine. The relative abundance of SCFA is also likely to differ along the length of the gut as a result of the region-specific microbial composition, substrate exposure, and absorption ( $\mathrm{Gu}$ et al., 2013). For example, genes encoding carbohydrate metabolism pathways are enriched in members of the Bacteroidetes phylum, while genes encoding bile acid metabolism pathways are enriched in the bile acid-tolerance Firmicutes (David et al., 2014).

Receptors present on EE cells allow these cells to sense luminal and possibly circulating SCFA, which triggers the release of several metabolically active gut hormones. SCFA signal via two predominant mechanisms: (1) inhibition of nuclear histone deacetylase (HDAC) (Waldecker et al., 2008; Fellows et al., 2018; Larraufie et al., 2018) to alter gene transcription and expression, and (2) stimulation of G-protein-coupled free fatty acid receptors 2 and 3 (FFAR3, FFAR3), expressed throughout the length of the GI tract in distinct regional patterns. FFAR2 has equal affinity for acetate, propionate and butyrate, while the affinity of FFAR3 for acetate is substantially lower than for propionate and butyrate (Offermanns, 2014). Signaling of SCFA via FFAR2/3 is therefore dependent upon the combination of receptor type and specific metabolite abundance.

\section{Secondary Bile Acids}

Bile acids are amphipathic molecules synthesized by hepatocytes from cholesterol and are released into the GI lumen to aid the solubilization, and thus absorption, of dietary lipids. It has long been appreciated that the intestinal microbiota is directly involved in host bile acid metabolism, as effective enterohepatic recycling of bile salts is heavily reliant on deconjugation and dihydroxylation of bile acids by microbialderived bile salt hydrolases (BSH). This gives rise to secondary bile acids (Jones et al., 2008), which are more hydrophobic and can thus be reabsorbed via passive diffusion, limiting bile acid loss through feces. Specific activity of $\mathrm{BSH}$ in human gut microbiota differs between different phyla, with $\mathrm{BSH}$ in the Firmicutes and Actinobacteria capable of metabolizing all conjugated bile salts and Bacteroidetes $\mathrm{BSH}$ activity being specific to tauro-conjugated bile acids (Jones et al., 2008). In addition to this role in the GI tract, bile acids are signaling molecules that are implicated in peripheral metabolism. Bile acids have major roles in peripheral metabolism through their action on two bile acid receptors, the G-protein coupled receptor TGR5 (formerly known as Gpbar1), and the nuclear receptor FXR, both 


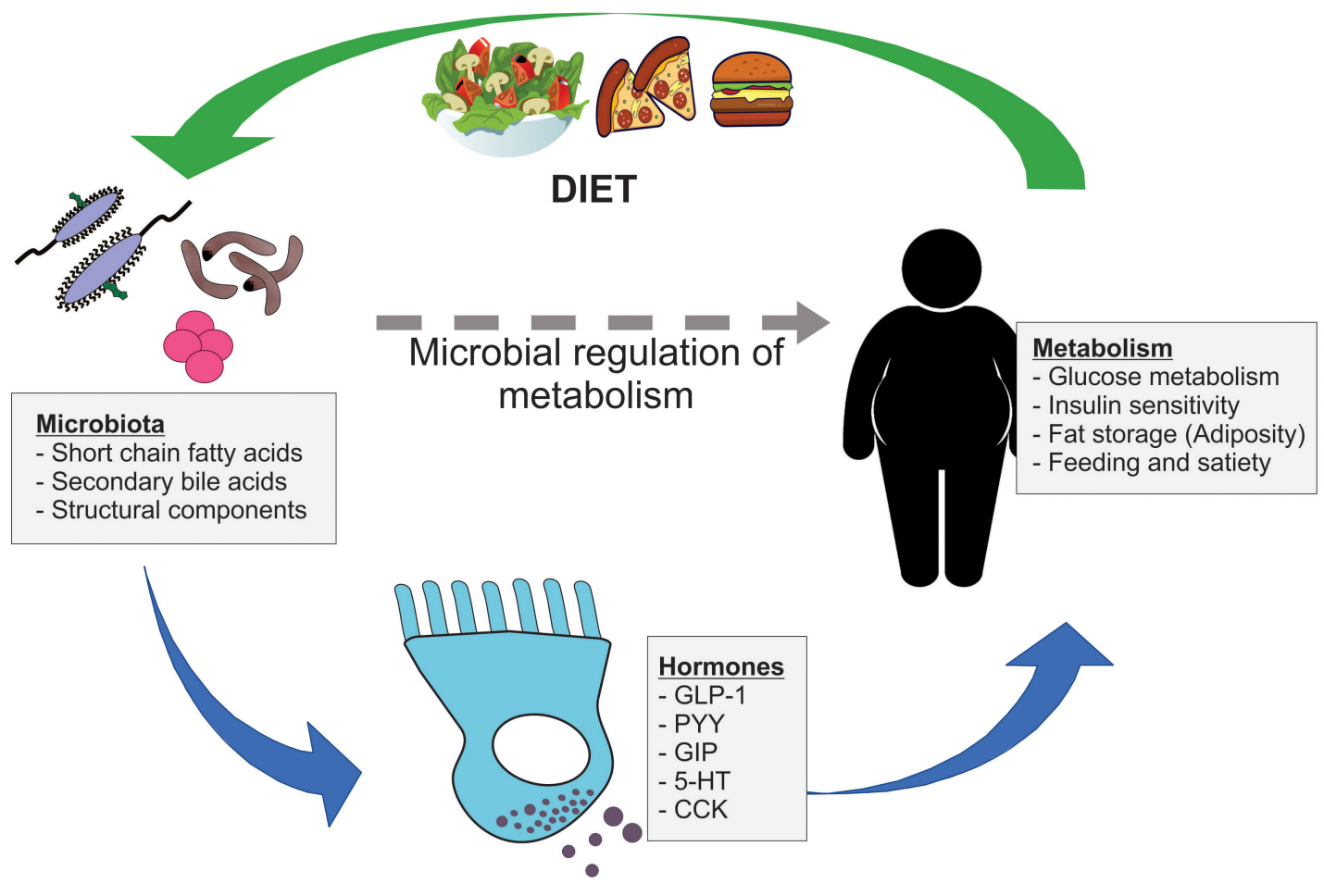

FIGURE 1 | Microbial regulation of host metabolism via gut hormone release. Gut microbiota signal to nearby enteroendocrine (EE) cells via a range of microbial metabolites, including short chain fatty acids and secondary bile acids, and structural components. These EE cells release important metabolically active hormones, such as GLP-1, PYY, GIP, 5-HT, and CCK, which influence key metabolic processes including glucose metabolism, insulin sensitivity, adiposity, and feeding behavior. In turn, dietary components impact the composition of gut microbiota, which may have further downstream consequences on gut hormone secretion and host metabolism.

of which are expressed in EE cells (Figure 2). Receptor affinity and potency varies substantially between different bile acids. As such, the gut microbiome can exert profound influence on host metabolism by altering the composition of the bile acid pool, through altered bile acid synthesis and re-uptake.

\section{Cellular Recognition of Microbial Structural Components}

Structural components of the microbial membrane, such as flagella and membrane-bound lipopolysaccharide (LPS), act as signaling molecules through a number of cellular pattern recognition proteins (Gordon, 2002). LPS is a cellwall component of Gram-negative bacteria, such as members of the Bacteroidetes phylum, and is a potent ligand for tolllike receptors (TLRs), particularly toll-like receptor 4 (TLR4). In addition to powerful immunity- and inflammation-inducing effects (Takeuchi and Akira, 2002; Lancaster et al., 2018), the expression of TLRs has been demonstrated in a number of EE cells and activation of this receptor triggers secretion of a number of metabolically active hormones such as GLP-1 (Lebrun et al., 2017), 5-HT (Kidd et al., 2009), and PYY (Larraufie et al., 2017; Figure 2). Clinically, elevated levels of LPS (endotoxemia) are closely associated with obesity and insulin resistance (Cani et al., 2007a). Mechanisms by which LPS contribute to perturbed glycemic control and adiposity likely involve complex interactions between gut hormone secretion, mucosal barrier integrity, and host inflammation and immune pathways.

\section{THE MICROBIOME REGULATES HOST METABOLISM VIA GUT HORMONE RELEASE}

\section{Serotonin}

Enterochromaffin (EC) cells are the source of almost all (about 95\%) serotonin (5-HT; 5-hydroxytryptamine) within the body. These cells constitute almost half of all EE cells and are dispersed throughout the length of the GI tract in varying densities (Raghupathi et al., 2013). EC cells have long been known to be important in many intrinsic gut mechanisms associated with motility (Keating and Spencer, 2010; Spencer et al., 2011, 2015; Spencer and Keating, 2016; Keating and Spencer, 2018) and EC cells are able to sense their local nutrient environment and respond by secreting 5 -HT in a unique manner (Zelkas et al., 2015; Raghupathi et al., 2016; Thorn et al., 2016). There is now firm evidence that gut-derived 5-HT is a key driver for dysregulation of peripheral metabolism (Sumara et al., 2012; Watanabe et al., 2014; Crane et al., 2015; Young et al., 2015, 2018; Martin et al., 2017c). The absence of gut-derived 5-HT, 


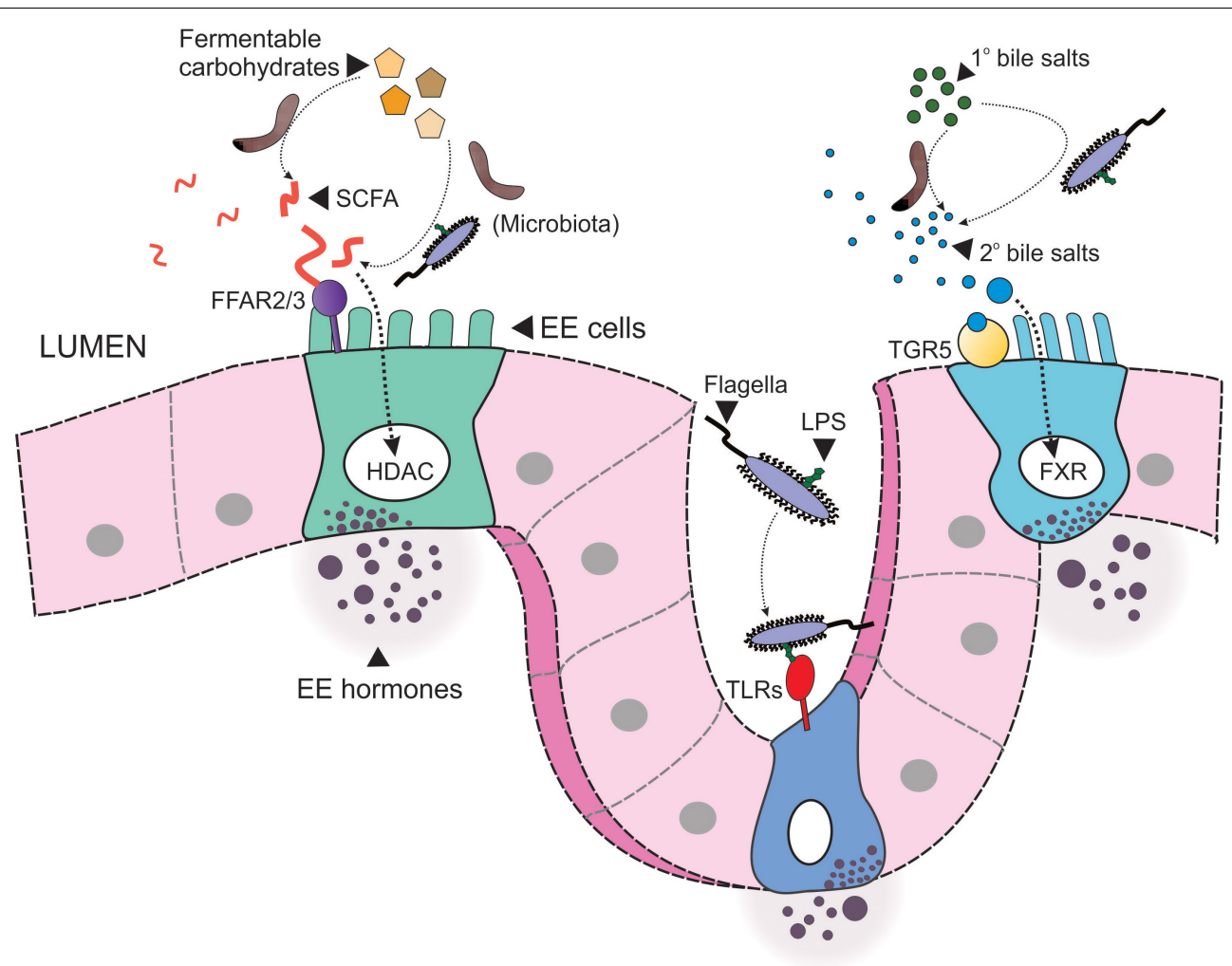

FIGURE 2 | Microbial signaling to enteroendocrine cells. Resident microbiota within the intestinal lumen signal to enteroendocrine (EE) cells via multiple pathways. Firstly, microbiota convert indigestible carbohydrates to short chain fatty acids (SCFA), which in turn signal to EE cells via free fatty acid receptors 2 or 3 (FFAR2/3) or by activation of nuclear histone deacetylases (HDAC). Secondly, microbiota convert primary $\left(1^{\circ}\right)$ bile acids to secondary $\left(2^{\circ}\right)$ bile acids, such as deoxycholate, which then signal to EE cells via the membrane G protein-coupled bile acid receptor, TGR5, or nuclear FXR. Finally, structural components of microbiota, such as flagella, and the endotoxin lipopolysaccharide (LPS), signal to toll-like receptors (TLRs).

through pharmacological inhibition or genetic ablation of the rate-limiting enzyme for 5-HT synthesis in the gut, tryptophan hydroxylase 1 (TPH1), conveys protection from diet-induced obesity in mice (Crane et al., 2015). Moreover, circulating 5-HT is increased in obese humans and is positively correlated with body mass index (Young et al., 2018) and poor glycaemic control (Takahashi et al., 2002).

The gut microbiome influences 5-HT levels in the host. GF and antibiotic-treated mice have substantially lower levels of EC cell-derived 5-HT when compared to conventionally raised (CONV-R) controls, which are restored by colonization of GF mice with donor gut microbiota (Yano et al., 2015). EC cells have the capacity to sense microbial metabolites, as they express both FFAR2 and FFAR3 (Akiba et al., 2015; Martin et al., 2017b), and a number of olfactory receptors (Bellono et al., 2017; Lund et al., 2018). Acute exposure of mouse primary EC cells to SCFA in culture does not, however, elicit an increase in 5-HT secretion (Martin et al., 2017a). Rather, the increase in 5-HT observed in the presence of a gut microbiome (Reigstad et al., 2015; Yano et al., 2015) is likely due to the chronic exposure mediating an increase in the biosynthesis of 5-HT, contributed to by increased EC cell proliferation (Yano et al., 2015). In addition, luminal butyrate infusion restores intestinal motility in GF mice, which is blunted in TPH1-KO mice, indicating the effects of butyrate may be mediated by EC cell 5-HT (Vincent et al., 2018). Acute responses to aromatic metabolites, such as isobutyrate and isovalerate, have been observed in EC cells within intestinal organoid preparations (Bellono et al., 2017), likely via olfactory receptor activation. However, it is plausible that this is an indirect response, due to the cross-talk with other gut-derived hormones such as GLP-1, which are also increased following exposure to microbial metabolites and have the capacity to signal to EC cells (Lund et al., 2018).

\section{GLP-1}

Glucagon-like peptide 1 (GLP-1), a cleavage product of proglucagon, is secreted by L-cells predominantly located in the ileum and colon. GLP-1 is an incretin hormone (Kreymann et al., 1987), released postprandially and in response to nutrients such as glucose (Sun et al., 2017) to augment insulin and inhibit glucagon secretion from the pancreas (Grondahl et al., 2017). In addition, GLP-1 inhibits gastric emptying and influences satiety and food intake (Holst, 2007). Together with PYY, GLP1 is thought to underlie some of the metabolic gains observed following gastric bypass surgery (Madsbad and Holst, 2014) and the action of GLP-1 underlies some of the glucose-lowering ability of the diabetes therapy, metformin (Bahne et al., 2018). As such, GLP-1-targeted therapeutics including GLP-1 analogs 
and inhibitors of GLP-1 degradation by the enzyme dipeptidyl peptidase IV (DPP-4) have been extensively exploited for their anti-diabetic properties (Aroda et al., 2012). Interestingly, the microbiota possess DPP-4-like activity (Olivares et al., 2018b), which in mice is reduced by administration of the DPP4 inhibitor, vildagliptin, and is accompanied by a shift in microbial composition that is independent of the direct effects of DPP-4 inhibition on microbiota function (Olivares et al., 2018a). Specifically, vildagliptin treatment is associated with a decrease in the abundance of Oscillibacter and increased in the abundance of Lactobacillus, with a reduction in TLR ligands and an increase in propionate (Olivares et al., 2018a). Thus, the DPP4 -like activity of intestinal bacteria can potentially influence the levels of circulating GLP-1 and PYY, which in turn may exist as a feedback loop to influence microbial composition and microbial metabolite abundance.

A dynamic relationship exists between L-cells and the gut microbiome. Bile acid-mediated activation of TGR5 (Bala et al., 2014), SCFA signaling (Tolhurst et al., 2012), LPS, and other metabolites such as indole (Chimerel et al., 2014) are all potent GLP-1 secretagogues. The regulation of GLP-1 by secondary bile acids is dependent upon the receptor-signaling pathway involved, as activation of TGR5 increases GLP-1 secretion while, on the other hand, activation of FXR reduces GLP1 secretion. This dynamic relationship is made even more complex by TGR5-FXR cross-talk that exists between these two receptors, particularly in the colon (Pathak et al., 2017). Luminal infusion of the bile acid chenodeoxycholic acid, in rats, triggers release of GLP-1 into the vasculature, in addition to PYY, via TGR5 (Kuhre et al., 2018). Indole, another major bacterial metabolite derived from dietary tryptophan, acutely stimulates GLP-1 by prolonging cellular action potential duration (Chimerel et al., 2014). Conversely, chronic exposure to indole dose-dependently decreases GLP-1 secretion in primary murine L cells by inhibiting ATP synthesis pathway (Chimerel et al., 2014). In addition, microbial LPS triggers GLP-1 secretion via TLR4 following mucosal barrier injury (Lebrun et al., 2017), and as such, glucose-stimulated insulin secretion in a mouse model of endotoxemia (Nguyen et al., 2014). Dietary prebiotics such as oligofructose, which increase bacterial SCFA production, are associated with upregulated L-cell differentiation and GLP1 content in the rat proximal colon, and reduces weight gain when administered before and during a HFD (Cani et al., 2007b). Increasing L-cell numbers, whereby increasing postprandial GLP-1 release, are also associated with enhanced satiety and reduced adiposity (Cani et al., 2007b). The mechanisms by which SCFA increase GLP-1 secretion are region-dependent, as signaling in the small intestine is predominantly via FFAR3, whereas FFAR2-mediated GLP-1 release occurs in the colon (Greiner and Backhed, 2016).

Paradoxically, GF and antibiotic-treated mice have higher circulating GLP-1 levels during fasting (Zarrinpar et al., 2018) and reduced mucosal GLP-1 content (Duca et al., 2012), compared to genetically identical CONV-R mice. A recent study (Arora et al., 2018) reported that the gene expression profile of ileal L-cells derived from GF mice differed substantially from CONV-R mice. Notably, many of the genes regulating L-cell functional capacity are upregulated in GF mice and L-cells have a greater number of secretory vesicles in GF mice. What underlies these differences in GF mice is unknown but may be a reflection of GLP-1 resistance, which is observed in diet-induced obesity and associated with altered microbiota composition, particularly in the ileum (Grasset et al., 2017).

\section{PYY}

Peptide tyrosine-tyrosine (PYY) is synthesized and secreted by L-cells, in addition to GLP-1, and is predominantly expressed in the lower small intestine and colon. PYY regulates food intake and satiety through activation of central $G$ protein-coupled Y2 receptors on neuropeptide Y (NPY) and AgRP neurons in the hypothalamic arcuate nucleus (Dumont et al., 1995). This initiates a signaling cascade whereby appetite-stimulating NPY neurons are suppressed, allowing for the disinhibition of the satiety-inducing proopiomelanocortin (POMC)/ $\alpha$-MSH pathway (Loh et al., 2015). Obese humans have reduced circulating PYY (Batterham et al., 2006), as a result of attenuated colonic PYY secretion (le Roux et al., 2006), rather than PYY-resistance (Batterham et al., 2003). Circulating PYY exists as two forms: $\mathrm{PYY}_{1-36}$ and the DPP-4-cleaved PYY $3-36$, with the latter being the most dominant postprandial circulating form (Grandt et al., 1994) and the most biologically potent with respect to its anorectic effects (Chelikani et al., 2006).

The ability of gut microbiota to influence PYY secretion therefore has significant implications for the development of obesity and metabolic disease. Microbial SCFAs, particularly butyrate, cause a dose- and time-dependent increase in PYY gene expression in two EE model cell lines and in primary human colonic cell cultures (Larraufie et al., 2018). In addition, oral administration of butyrate moderately increases circulating PYY (Lin et al., 2012). The mechanisms by which SCFA increase the biosynthesis of PYY appear to be via a combination of FFAR2/3 signaling by all SCFA, and inhibition of HCAD by propionate and butyrate (Larraufie et al., 2018). Although, these mechanisms appear to be species-specific (Larraufie et al., 2018) and were not accompanied by an increase in GLP-1 secretion that is seen following exposure of primary mouse colonic cultures to propionate (Psichas et al., 2015). The use of a FFAR2 knockout mouse demonstrates the involvement of SCFA signaling in increasing the number of PYY-containing cells, particularly in mice exposed to a diet rich in the SCFA-precursor, inulin (Brooks et al., 2017). Alteration of the human gut microbiota through a 4-day broad-spectrum antibiotic regimen, acutely and reversibly increased postprandial plasma PYY (Mikkelsen et al., 2015). However, the precise alterations in microbial metabolites and bacterial species that underlie this change are unknown. Secondary bile acids are also potent stimuli for PYY secretion and the mechanisms by which this occurs are consistent with those for GLP-1 secretion (Kuhre et al., 2018). Luminal perfusion of a mixture of both primary and secondary bile acids into a vascularly perfused rat lumen increases venous effluent PYY levels in a TGR5-dependent manner, while the same effect was observed with infusion of the secondary bile acid CDCA alone (Kuhre et al., 2018). 


\section{GIP}

Glucose-dependent insulinotropic peptide (GIP), also known as gastric inhibitory peptide, is an incretin hormone released postprandially in the small intestine from classically defined K cells (Buffa et al., 1975). The activity of GIP is conveyed through GIP receptors (GIPR) expressed in pancreatic $\beta$-cells (Gremlich et al., 1995), adipocytes (Yip et al., 1998), bone cells (Bollag et al., 2000), and in neurons of the CNS (Paratore et al., 2011). Similar to GLP-1, the biological activity of GIP is rapidly attenuated by enzymatic breakdown by DPP-IV (Baggio and Drucker, 2007). Within the pancreas, GIP contributes significantly to postprandial insulin secretion, through increased insulin biosynthesis (Baggio and Drucker, 2007) and upregulated $\beta$-cell proliferation (Widenmaier et al., 2009). Defective GIPsignaling is believed to underlie, at least in part, the attenuated glucose-stimulated insulin secretion seen in T2D individuals (Vilsboll et al., 2002). GIP is also widely considered an adipogenic hormone (Thondam et al., 2017) as it promotes lipid uptake and storage in adipocytes (Getty-Kaushik et al., 2006).

Elevated GIP level was associated with the observed increased adiposity induced by a sub-therapeutic antibiotic regimen administered to mice at weaning for 7-weeks, as the treatment did not alter plasma levels of other gut hormones (Cho et al., 2012). The treatment significantly increased Firmicutes/Bacteroidetes ratio and caecal SCFA levels, which could potentially underlie the increased GIP level and thus, the increased adiposity. However, recent contradictory evidence demonstrates that carbohydrates within the lumen inhibit GIP secretion, via the microbial SCFA-FFAR3 signaling pathway (Lee et al., 2018). Whether the discrepancy seen across these studies is due to differential signaling via FFAR2 and FFAR3 is unknown. Consistent with specific receptor pathways for SCFA-mediated gut hormone release, oral administration of sodium butyrate into mice has been shown to transiently increase GIP and GLP-1 secretion, while sodium pyruvate and a SCFA cocktail are selective for increased GIP, but not GLP-1 or PYY (Lin et al., 2012).

\section{CCK}

Cholecystokinin (CCK) is derived from the classically named "I cells" predominantly localized to the upper small intestine (Dockray, 2012). CCK is released in response to dietary fat and protein intake. CCK has well-defined roles in appetite regulation (Ritter, 2004; Becskei et al., 2007), gastric emptying and motility (Raybould and Tache, 1988; Raybould, 1991; Ellis et al., 2013) and the release of bile acids and pancreatic enzymes that are important for digestion ( $\mathrm{Li}$ and Owyang, 1994; Li and Owyang, 1996; Owyang and Logsdon, 2004), through activation of CCK receptors (Rogers and Hermann, 2008). Less is known about gut microbial regulation of CCK compared to other gut hormones, largely due to the exposure of CCK-containing cells to microbiota limited to the small intestine. In pigs, ileal infusion of the SCFAs acetate, propionate and butyrate during feeding increased plasma CCK levels and paradoxically inhibits pancreatic secretion (Sileikiene et al., 2008). Limited investigations have been undertaken into microbial regulation of CCK in humans, however. One report from Roux-en-Y gastric bypass patients has revealed no changes in circulating CCK levels across normal weight and obese individuals pre- and post-surgery, despite a significant shift in microbial composition following surgery (Federico et al., 2016). However, reduced CCK protein expression is observed in dissociated cells from the proximal small intestine of GF mice, which was not due to reduced numbers of EE cells (Duca et al., 2012).

\section{Diet Influences Gut Microbiota Composition}

The diversity of gut microbiota and relative abundance of microbial metabolites (metabolomic profile) is heavily dependent on specific dietary components (David et al., 2014), as evidenced by the substantial difference in microbial communities with consumption of plant-rich or protein-rich diets. This is due to the nutrient-induced selective pressures placed on microbiota, favoring bacterial species enrichened in the genes required for specific substrate metabolism. For example, plant-based diets and intake of probiotics increases luminal fiber and complex carbohydrate content, whereby selecting for species enriched in carbohydrate-active enzymes (David et al., 2014). Animalbased diets rich in fats and proteins and low in fiber increase luminal bile acid content, favoring bile acid-resistant microbes enriched with genes for bile acid metabolism, such as bile acid hydrosases and sulfite reductase (Devkota et al., 2012; David et al., 2014). Dietary fiber is also a major influence on gut transit (reviewed in detail by Muller et al., 2018), which, in turn, is an important determinant of fecal microbiome composition and metabolism (Roager et al., 2016; Vandeputte et al., 2016). In the absence of dietary fiber, however, a compensatory shift in the gut microbiome has been observed, with an increase in populations expressing mucin-degrading enzymes, suggesting an overall microbial preference for fiberbased substrates (Desai et al., 2016).

The increased consumption of non-nutritive sweeteners (NNS), such as saccharin, sucralose and aspartame, while being acutely beneficial for reducing caloric intake and blood glucose excursions, also has long-term consequences for microbiome composition and glucose intolerance. Notably, consumption of common NNS has been demonstrated in mice to exacerbate the development of glucose intolerance (Suez et al., 2014, 2015) and weight gain in males (Bian et al., 2017), which is mediated by distinct functional alterations to the gut microbiome (Suez et al., 2014). Specifically, the NNS saccharin and acesulfame-K increased the abundance of members of Bacteroidetes (Suez et al., 2014; Bian et al., 2017) and reduced abundance of Firmicutes (Suez et al., 2014). The effects of NNS on metabolism and microbial composition in humans is largely dictated by the native microbial composition prior to NNS exposure (Suez et al., 2014), while in mice, the response also appears to be genderspecific (Bian et al., 2017). Nevertheless, the NNS-induced changes in microbial composition observed in these studies is consistent with the microbial composition seen with obesity and metabolic disease (Ley et al., 2006; Turnbaugh and Gordon, 2009; Turnbaugh et al., 2009). 
The richness and diversity of the human gut microbiome correlates with metabolic function (Le Chatelier et al., 2013; David et al., 2014; Dao et al., 2016) and a core obesogenic microbiome has been established, characterized by a high ratio of Firmicutes to Bacteroidetes (Ley et al., 2006; Turnbaugh and Gordon, 2009; Turnbaugh et al., 2009). Shifting the composition of the microbiome to reduce the abundance of Bacteroidetes, as seen with short-term caloric restriction, conveys improved metabolic outcomes in mice as a result of decreased LPS production and reduced TLR4 signaling (Fabbiano et al., 2018). There are also large-scale observational studies that linked antibiotic use to risk of type 2 diabetes (Boursi et al., 2015; Mikkelsen et al., 2015), although caution should be excised in interpreting these results, as hyperglycaemia is a risk factor for infection (Falagas and Kompoti, 2006) and may thus warrant increased antibiotic use. In addition, specific clinically used antibiotics, particularly vancomycin-imipenem and ciprofloxacin, induce differential effects on microbiome composition and microbial metabolite abundance following regrowth (Choo et al., 2017), which may have downstream implications for antibioticspecific effects on metabolism. Ingestion of xenobiotics, such as pharmaceuticals and environmental chemicals, has the potential to modify gut microbial composition with downstream consequences for metabolism. This is evidenced by the diabetes drug, metformin, for which a shift in gut microbial composition is in part responsible for its therapeutic

\section{REFERENCES}

Aguirre, M., Eck, A., Koenen, M. E., Savelkoul, P. H., Budding, A. E., and Venema, K. (2016). Diet drives quick changes in the metabolic activity and composition of human gut microbiota in a validated in vitro gut model. Res. Microbiol. 167, 114-125. doi: 10.1016/j.resmic.2015. 09.006

Ahlman, H., and Nilsson, O. (2001). The gut as the largest endocrine organ in the body. Ann. Oncol. 12, S63-S68. doi: 10.1093/annonc/12.suppl_2.S63

Akiba, Y., Inoue, T., Kaji, I., Higashiyama, M., Narimatsu, K., Iwamoto, K., et al. (2015). Short-chain fatty acid sensing in rat duodenum. J. Physiol. 593, 585-599. doi: 10.1113/jphysiol.2014.280792

Aroda, V. R., Henry, R. R., Han, J., Huang, W., DeYoung, M. B., Darsow, T., et al. (2012). Efficacy of GLP-1 receptor agonists and DPP-4 inhibitors: metaanalysis and systematic review. Clin. Ther. 34, 1247.e22-1258.e22. doi: 10.1016/ j.clinthera.2012.04.013

Arora, T., Akrami, R., Pais, R., Bergqvist, L., Johansson, B. R., Schwartz, T. W., et al. (2018). Microbial regulation of the L cell transcriptome. Sci. Rep. 8:1207. doi: 10.1038/s41598-017-18079-2

Baggio, L. L., and Drucker, D. J. (2007). Biology of incretins: GLP-1 and GIP. Gastroenterology 132, 2131-2157. doi: 10.1053/j.gastro.2007.03.054

Bahne, E., Sun, E. W. L., Young, R. L., Hansen, M., Sonne, D. P., Hansen, J. S., et al. (2018). Metformin-induced glucagon-like peptide-1 secretion contributes to the actions of metformin in type 2 diabetes. JCI Insight 3:93936. doi: 10.1172/ jci.insight.93936

Bala, V., Rajagopal, S., Kumar, D. P., Nalli, A. D., Mahavadi, S., Sanyal, A. J., et al. (2014). Release of GLP-1 and PYY in response to the activation of G proteincoupled bile acid receptor TGR5 is mediated by Epac/PLC-epsilon pathway and modulated by endogenous H2S. Front. Physiol. 5:420. doi: 10.1007/s00125-0184647-6

Batterham, R. L., Cohen, M. A., Ellis, S. M., Le Roux, C. W., Withers, D. J., Frost, G. S., et al. (2003). Inhibition of food intake in obese subjects by peptide YY3-36. N. Engl. J. Med. 349, 941-948. doi: 10.1056/NEJMoa030204 effects (Wu et al., 2017). The metabolism of xenobiotics by gut microbiota is also chemically distinct (Koppel et al., 2017), which highlights the gut microbiome as a possible tool for targeted drug design and delivery. Recent work by Vangay et al. (2018) has elegantly shown that migration from a non-Westernized culture to a Westernized culture rapidly and inter-generationally impacts the diversity of gut microbiota. This loss of microbial complexity and biodiversity resulted in a loss of key microbial enzymes required for plant fiber digestion, partly attributed to altered dietary composition and reduced food diversity, and may predispose individuals to metabolic disease (Vangay et al., 2018). As such, interventions to shift gut microbiota composition may be a powerful therapeutic tool for the treatment of obesity and metabolic disorders.

\section{AUTHOR CONTRIBUTIONS}

All authors listed have made a substantial, direct and intellectual contribution to the work, and approved it for publication.

\section{FUNDING}

DK was supported by a research fellowship from the National Health and Medical Research Council (NHMRC) of Australia.

Batterham, R. L., Heffron, H., Kapoor, S., Chivers, J. E., Chandarana, K., Herzog, H., et al. (2006). Critical role for peptide YY in protein-mediated satiation and body-weight regulation. Cell Metab. 4, 223-233. doi: 10.1016/j.cmet.2006. 08.001

Becskei, C., Grabler, V., Edwards, G. L., Riediger, T., and Lutz, T. A. (2007). Lesion of the lateral parabrachial nucleus attenuates the anorectic effect of peripheral amylin and CCK. Brain Res. 1162, 76-84. doi: 10.1016/j.brainres.2007.06.016

Belkaid, Y., and Hand, T. W. (2014). Role of the microbiota in immunity and inflammation. Cell 157, 121-141. doi: 10.1016/j.cell.2014.03.011

Bellono, N. W., Bayrer, J. R., Leitch, D. B., Castro, J., Zhang, C., O’Donnell, T. A., et al. (2017). Enterochromaffin cells are gut chemosensors that couple to sensory neural pathways. Cell 170, 185.e16-198.e16. doi: 10.1016/j.cell.2017.05.034

Bian, X., Chi, L., Gao, B., Tu, P., Ru, H., and Lu, K. (2017). The artificial sweetener acesulfame potassium affects the gut microbiome and body weight gain in CD-1 mice. PLoS One 12:e0178426. doi: 10.1371/journal.pone.0178426

Blaut, M. (2015). Gut microbiota and energy balance: role in obesity. Proc. Nutr. Soc. 74, 227-234. doi: 10.1017/S0029665114001700

Bollag, R. J., Zhong, Q., Phillips, P., Min, L., Zhong, L., Cameron, R., et al. (2000). Osteoblast-derived cells express functional glucose-dependent insulinotropic peptide receptors. Endocrinology 141, 1228-1235. doi: 10.1210/endo.141.3.7366

Boursi, B., Mamtani, R., Haynes, K., and Yang, Y. X. (2015). The effect of past antibiotic exposure on diabetes risk. Eur. J. Endocrinol. 172, 639-648. doi: 10.1530/EJE-14-1163

Brooks, L., Viardot, A., Tsakmaki, A., Stolarczyk, E., Howard, J. K., Cani, P. D., et al. (2017). Fermentable carbohydrate stimulates FFAR2-dependent colonic PYY cell expansion to increase satiety. Mol. Metab. 6, 48-60. doi: 10.1016/j. molmet.2016.10.011

Brubaker, P. L. (2018). Linking the gut microbiome to metabolism through endocrine hormones. Endocrinology 159, 2978-2979. doi: 10.1210/en.201800577

Buffa, R., Polak, J. M., Pearse, A. G., Solcia, E., Grimelius, L., and Capella, C. (1975). Identification of the intestinal cell storing gastric inhibitory peptide. Histochemistry 43, 249-255. doi: 10.1007/BF00499706 
Cani, P. D., Amar, J., Iglesias, M. A., Poggi, M., Knauf, C., Bastelica, D., et al. (2007a). Metabolic endotoxemia initiates obesity and insulin resistance. Diabetes Metab. Res. Rev. 56, 1761-1772.

Cani, P. D., Hoste, S., Guiot, Y., and Delzenne, N. M. (2007b). Dietary nondigestible carbohydrates promote L-cell differentiation in the proximal colon of rats. Br. J. Nutr. 98, 32-37. doi: 10.1017/S0007114507691648

Chelikani, P. K., Haver, A. C., Reeve, J. R. Jr., Keire, D. A., and Reidelberger, R. D. (2006). Daily, intermittent intravenous infusion of peptide YY(3-36) reduces daily food intake and adiposity in rats. Am. J. Physiol. Regul. Integr. Comp. Physiol. 290, R298-R305. doi: 10.1152/ajpregu.00674.2005

Chimerel, C., Emery, E., Summers, D. K., Keyser, U., Gribble, F. M., and Reimann, F. (2014). Bacterial metabolite indole modulates incretin secretion from intestinal enteroendocrine L cells. Cell Rep. 9, 1202-1208. doi: 10.1016/j. celrep.2014.10.032

Cho, I., Yamanishi, S., Cox, L., Methe, B. A., Zavadil, J., Li, K., et al. (2012). Antibiotics in early life alter the murine colonic microbiome and adiposity. Nature 488, 621-626. doi: 10.1038/nature11400

Choo, J. M., Kanno, T., Zain, N. M., Leong, L. E., Abell, G. C., Keeble, J. E., et al. (2017). Divergent relationships between fecal microbiota and metabolome following distinct antibiotic-induced disruptions. mSphere 2:e0005-17.

Crane, J. D., Palanivel, R., Mottillo, E. P., Bujak, A. L., Wang, H., Ford, R. J., et al. (2015). Inhibiting peripheral serotonin synthesis reduces obesity and metabolic dysfunction by promoting brown adipose tissue thermogenesis. Nat. Med. 21, 166-172. doi: 10.1038/nm.3766

Cuche, G., and Malbert, C. H. (1999). Short-chain fatty acids present in the ileum inhibit fasting gastrointestinal motility in conscious pigs. Neurogastroenterol. Motil. 11, 219-225. doi: 10.1046/j.1365-2982.1999.00149.x

Cummings, J. H., Pomare, E. W., Branch, W. J., Naylor, C. P., and Macfarlane, G. T. (1987). Short chain fatty acids in human large intestine, portal, hepatic and venous blood. Gut 28, 1221-1227. doi: 10.1136/gut.28.10.1221

Dao, M. C., Everard, A., Aron-Wisnewsky, J., Sokolovska, N., Prifti, E., Verger, E. O., et al. (2016). Akkermansia muciniphila and improved metabolic health during a dietary intervention in obesity: relationship with gut microbiome richness and ecology. Gut 65, 426-436. doi: 10.1136/gutjnl-2014308778

David, L. A., Maurice, C. F., Carmody, R. N., Gootenberg, D. B., Button, J. E., Wolfe, B. E., et al. (2014). Diet rapidly and reproducibly alters the human gut microbiome. Nature 505, 559-563. doi: 10.1038/nature12820

Desai, M. S., Seekatz, A. M., Koropatkin, N. M., Kamada, N., Hickey, C. A., Wolter, M., et al. (2016). A dietary fiber-deprived gut microbiota degrades the colonic mucus barrier and enhances pathogen susceptibility. Cell 167, 1339.e21-1353.e21. doi: 10.1016/j.cell.2016.10.043

Devkota, S., Wang, Y., Musch, M. W., Leone, V., Fehlner-Peach, H., Nadimpalli, A., et al. (2012). Dietary-fat-induced taurocholic acid promotes pathobiont expansion and colitis in Il10-/- mice. Nature 487, 104-108. doi: 10.1038/ nature 11225

Dockray, G. J. (2012). Cholecystokinin. Curr. Opin. Endocrinol. Diabetes Obes. 19, 8-12. doi: 10.1097/MED.0b013e32834eb77d

Duca, F. A., Swartz, T. D., Sakar, Y., and Covasa, M. (2012). Increased oral detection, but decreased intestinal signaling for fats in mice lacking gut microbiota. PLoS One 7:e39748. doi: 10.1371/journal.pone.0039748

Dumont, Y., Fournier, A., St-Pierre, S., and Quirion, R. (1995). Characterization of neuropeptide $\mathrm{Y}$ binding sites in rat brain membrane preparations using [125I][Leu31,Pro34]peptide YY and [125I]peptide YY3-36 as selective Y1 and Y2 radioligands. J. Pharmacol. Exp. Ther. 272, 673-680.

Ellis, M., Chambers, J. D., Gwynne, R. M., and Bornstein, J. C. (2013). Serotonin and cholecystokinin mediate nutrient-induced segmentation in guinea pig small intestine. Am. J. Physiol. Gastrointest. Liver Physiol. 304, G749-G761. doi: 10.1152/ajpgi.00358.2012

Fabbiano, S., Suarez-Zamorano, N., Chevalier, C., Lazarevic, V., Kieser, S., Rigo, D., et al. (2018). Functional gut microbiota remodeling contributes to the caloric restriction-induced metabolic improvements. Cell Metab. 28, 907.e7-921.e7. doi: 10.1016/j.cmet.2018.08.005

Falagas, M. E., and Kompoti, M. (2006). Obesity and infection. Lancet Infect. Dis. 6, 438-446. doi: 10.1016/S1473-3099(06)70523-0

Federico, A., Dallio, M., Tolone, S., Gravina, A. G., Patrone, V., Romano, M., et al. (2016). Gastrointestinal hormones, intestinal microbiota and metabolic homeostasis in obese patients: effect of bariatric surgery. In Vivo 30, 321-330.
Fellows, R., Denizot, J., Stellato, C., Cuomo, A., Jain, P., Stoyanova, E., et al. (2018). Microbiota derived short chain fatty acids promote histone crotonylation in the colon through histone deacetylases. Nat. Commun. 9:105. doi: 10.1038/s41467017-02651-5

Fothergill, L. J., Callaghan, B., Hunne, B., Bravo, D. M., and Furness, J. B. (2017). Co-storage of enteroendocrine hormones evaluated at the cell and subcellular levels in male mice. Endocrinology 158, 2113-2123. doi: 10.1210/en.201700243

Getty-Kaushik, L., Song, D. H., Boylan, M. O., Corkey, B. E., and Wolfe, M. M. (2006). Glucose-dependent insulinotropic polypeptide modulates adipocyte lipolysis and reesterification. Obesity 14, 1124-1131. doi: 10.1038/oby.2006.129

Gordon, S. (2002). Pattern recognition receptors: doubling up for the innate immune response. Cell 111, 927-930. doi: 10.1016/S0092-8674(02)01201-1

Grandt, D., Schimiczek, M., Beglinger, C., Layer, P., Goebell, H., Eysselein, V. E., et al. (1994). Two molecular forms of peptide YY (PYY) are abundant in human blood: characterization of a radioimmunoassay recognizing PYY 1-36 and PYY 3-36. Regul. Pept. 51, 151-159. doi: 10.1016/0167-0115(94)90204-6

Grasset, E., Puel, A., Charpentier, J., Collet, X., Christensen, J. E., Terce, F., et al. (2017). A specific gut microbiota dysbiosis of type 2 diabetic mice induces GLP1 resistance through an enteric NO-dependent and gut-brain axis mechanism. Cell Metab. 25, 1075.e5-1090.e5. doi: 10.1016/j.cmet.2017.06.003

Greiner, T. U., and Backhed, F. (2016). Microbial regulation of GLP-1 and L-cell biology. Mol. Metab. 5, 753-758. doi: 10.1016/j.molmet.2016.05.012

Gremlich, S., Porret, A., Hani, E. H., Cherif, D., Vionnet, N., Froguel, P., et al. (1995). Cloning, functional expression, and chromosomal localization of the human pancreatic islet glucose-dependent insulinotropic polypeptide receptor. Diabetes Metab. Res. Rev. 44, 1202-1208.

Grondahl, M. F., Keating, D. J., Vilsboll, T., and Knop, F. K. (2017). Current therapies that modify glucagon secretion: what is the therapeutic effect of such modifications? Curr. Diabetes Rep. 17:128. doi: 10.1007/s11892-017-0967-z

Gu, S., Chen, D., Zhang, J. N., Lv, X., Wang, K., Duan, L. P., et al. (2013). Bacterial community mapping of the mouse gastrointestinal tract. PLoS One 8:e74957. doi: 10.1371/journal.pone.0074957

Hartstra, A. V., Bouter, K. E., Backhed, F., and Nieuwdorp, M. (2015). Insights into the role of the microbiome in obesity and type 2 diabetes. Diabetes Care 38, 159-165. doi: 10.2337/dc14-0769

Holst, J. J. (2007). The physiology of glucagon-like peptide 1. Physiol. Rev. 87, 1409-1439. doi: 10.1152/physrev.00034.2006

Jones, B. V., Begley, M., Hill, C., Gahan, C. G., and Marchesi, J. R. (2008). Functional and comparative metagenomic analysis of bile salt hydrolase activity in the human gut microbiome. Proc. Natl. Acad. Sci. U.S.A. 105, 13580-13585. doi: $10.1073 /$ pnas.0804437105

Keating, D. J., and Spencer, N. J. (2010). Release of 5-hydroxytryptamine from the mucosa is not required for the generation or propagation of colonic migrating motor complexes. Gastroenterology 138, 659-670, 670.e1-2. doi: 10. 1053/j.gastro.2009.09.020

Keating, D. J., and Spencer, N. J. (2018). What is the role of endogenous gut serotonin in the control of gastrointestinal motility? Pharmacol. Res. 140, 50-55. doi: $10.1016 /$ j.phrs.2018.06.017

Kidd, M., Gustafsson, B. I., Drozdov, I., and Modlin, I. M. (2009). IL1beta- and LPS-induced serotonin secretion is increased in EC cells derived from Crohn's disease. Neurogastroenterol. Motil. 21, 439-450. doi: 10.1111/j.1365-2982.2008. 01210.x

Koh, A., De Vadder, F., Kovatcheva-Datchary, P., and Backhed, F. (2016). From dietary fiber to host physiology: short-chain fatty acids as key bacterial metabolites. Cell 165, 1332-1345. doi: 10.1016/j.cell.2016.05.041

Koppel, N., Maini Rekdal, V. and Balskus, E. P. (2017). Chemical transformation of xenobiotics by the human gut microbiota. Science 356:eaag2770. doi: 10.1126/ science.aag 2770

Koskinen, K., Pausan, M. R., Perras, A. K., Beck, M., Bang, C., Mora, M., et al. (2017). First insights into the diverse human archaeome: specific detection of archaea in the gastrointestinal tract, lung, and nose and on skin. mBio 8 , e824-e817. doi: 10.1128/mBio.00824-17

Kreymann, B., Williams, G., Ghatei, M. A., and Bloom, S. R. (1987). Glucagonlike peptide-1 7-36: a physiological incretin in man. Lancet 2, 1300-1304. doi: 10.1016/S0140-6736(87)91194-9

Kuhre, R. E., Wewer Albrechtsen, N. J., Larsen, O., Jepsen, S. L., Balk-Moller, E., Andersen, D. B., et al. (2018). Bile acids are important direct and indirect 
regulators of the secretion of appetite- and metabolism-regulating hormones from the gut and pancreas. Mol. Metab. 11, 84-95. doi: 10.1016/j.molmet.2018. 03.007

Laforest-Lapointe, I., and Arrieta, M. C. (2018). Microbial eukaryotes: a missing link in gut microbiome studies. mSystems 3:e00201-17.

Lam, Y. Y., Ha, C. W., Campbell, C. R., Mitchell, A. J., Dinudom, A., Oscarsson, J., et al. (2012). Increased gut permeability and microbiota change associate with mesenteric fat inflammation and metabolic dysfunction in diet-induced obese mice. PLoS One 7:e34233. doi: 10.1371/journal.pone.0034233

Lancaster, G. I., Langley, K. G., Berglund, N. A., Kammoun, H. L., Reibe, S., Estevez, E., et al. (2018). Evidence that TLR4 is not a receptor for saturated fatty acids but mediates lipid-induced inflammation by reprogramming macrophage metabolism. Cell Metab. 27, 1096.e5-1110.e5. doi: 10.1016/j.cmet.2018.03.014

Larraufie, P., Dore, J., Lapaque, N., and Blottiere, H. M. (2017). TLR ligands and butyrate increase Pyy expression through two distinct but inter-regulated pathways. Cell Microbiol. 19:e12648. doi: 10.1111/cmi.12648

Larraufie, P., Martin-Gallausiaux, C., Lapaque, N., Dore, J., Gribble, F. M., Reimann, F., et al. (2018). SCFAs strongly stimulate PYY production in human enteroendocrine cells. Sci. Rep. 8:74. doi: 10.1038/s41598-017-18259-0

Le Chatelier, E., Nielsen, T., Qin, J., Prifti, E., Hildebrand, F., Falony, G., et al. (2013). Richness of human gut microbiome correlates with metabolic markers. Nature 500, 541-546. doi: 10.1038/nature12506

le Roux, C. W., Batterham, R. L., Aylwin, S. J., Patterson, M., Borg, C. M., Wynne, K. J., et al. (2006). Attenuated peptide YY release in obese subjects is associated with reduced satiety. Endocrinology 147, 3-8. doi: 10.1210/en.2005-0972

Lebrun, L. J., Lenaerts, K., Kiers, D., Pais, de Barros, J. P., Le Guern, N., et al. (2017). Enteroendocrine L cells sense LPS after gut barrier injury to enhance GLP-1 secretion. Cell Rep. 21, 1160-1168. doi: 10.1016/j.celrep.2017.10.008

Lee, E. Y., Zhang, X., Miyamoto, J., Kimura, I., Taknaka, T., Furusawa, K., et al. (2018). Gut carbohydrate inhibits GIP secretion via a microbiota/SCFA/FFAR3 pathway. J. Endocrinol. 239, 267-276. doi: 10.1530/JOE-18-0241

Ley, R. E., Turnbaugh, P. J., Klein, S., and Gordon, J. I. (2006). Microbial ecology: human gut microbes associated with obesity. Nature 444, 1022-1023. doi: 10 . $1038 / 4441022 \mathrm{a}$

Li, Y., and Owyang, C. (1994). Endogenous cholecystokinin stimulates pancreatic enzyme secretion via vagal afferent pathway in rats. Gastroenterology 107, 525-531. doi: 10.1016/0016-5085(94)90180-5

Li, Y., and Owyang, C. (1996). Pancreatic secretion evoked by cholecystokinin and non-cholecystokinin-dependent duodenal stimuli via vagal afferent fibres in the rat. J. Physiol. 494(Pt 3), 73-82. doi: 10.1113/jphysiol.1996.sp021531

Lin, H. V., Frassetto, A., Kowalik, E. J. Jr., Nawrocki, A. R., Lu, M. M., et al. (2012). Butyrate and propionate protect against diet-induced obesity and regulate gut hormones via free fatty acid receptor 3 -independent mechanisms. PLoS One 7:e35240. doi: 10.1371/journal.pone.0035240

Loh, K., Herzog, H., and Shi, Y. C. (2015). Regulation of energy homeostasis by the NPY system. Trends Endocrinol. Metab. 26, 125-135. doi: 10.1016/j.tem.2015. 01.003

Lund, M. L., Egerod, K. L., Engelstoft, M. S., Dmytriyeva, O., Theodorsson, E., Patel, B. A., et al. (2018). Enterochromaffin 5-HT cells - A major target for GLP-1 and gut microbial metabolites. Mol. Metab. 11, 70-83. doi: 10.1016/j.molmet.2018. 03.004

Madsbad, S., and Holst, J. J. (2014). GLP-1 as a mediator in the remission of type 2 diabetes after gastric bypass and sleeve gastrectomy surgery. Diabetes Metab. Res. Rev. 63, 3172-3174. doi: 10.2337/db14-0935

Martin, A. M., Lumsden, A. L., Young, R. L., Jessup, C. F., Spencer, N. J., and Keating, D. J. (2017a). Regional differences in nutrient-induced secretion of gut serotonin. Physiol. Rep. 5:e13199. doi: 10.14814/phy2.13199

Martin, A. M., Lumsden, A. L., Young, R. L., Jessup, C. F., Spencer, N. J., and Keating, D. J. (2017b). The nutrient-sensing repertoires of mouse enterochromaffin cells differ between duodenum and colon. Neurogastroenterol. Motil. 29:e13046. doi: 10.1111/nmo.13046

Martin, A. M., Young, R. L., Leong, L., Rogers, G. B., Spencer, N. J., Jessup, C. F., et al. (2017c). The diverse metabolic roles of peripheral serotonin. Endocrinology 158, 1049-1063. doi: 10.1210/en.2016-1839

Mikkelsen, K. H., Frost, M., Bahl, M. I., Licht, T. R., Jensen, U. S., Rosenberg, J., et al. (2015). Effect of antibiotics on gut microbiota, gut hormones and glucose metabolism. PLoS One 10:e0142352. doi: 10.1371/journal.pone.0142352
Molinaro, A., Caesar, R., Holm, L. M., Tremaroli, V., Cani, P. D., and Backhed, F. (2017). Host-microbiota interaction induces bi-phasic inflammation and glucose intolerance in mice. Mol. Metab. 6, 1371-1380. doi: 10.1016/j.molmet. 2017.08.016

Mowat, A. M., and Agace, W. W. (2014). Regional specialization within the intestinal immune system. Nat. Rev. Immunol. 14, 667-685. doi: 10.1038/ nri3738

Muller, M., Canfora, E. E., and Blaak, E. E. (2018). Gastrointestinal transit time, glucose homeostasis and metabolic health: modulation by dietary fibers. Nutrients 10:275. doi: 10.3390/nu10030275

Nguyen, A. T., Mandard, S., Dray, C., Deckert, V., Valet, P., Besnard, P., et al. (2014). Lipopolysaccharides-mediated increase in glucose-stimulated insulin secretion: involvement of the GLP-1 pathway. Diabetes Metab. Res. Rev. 63, 471-482. doi: $10.2337 / \mathrm{db} 13-0903$

Nieuwdorp, M., Gilijamse, P. W., Pai, N., and Kaplan, L. M. (2014). Role of the microbiome in energy regulation and metabolism. Gastroenterology 146, 1525-1533. doi: 10.1053/j.gastro.2014.02.008

Offermanns, S. (2014). Free fatty acid (FFA) and hydroxy carboxylic acid (HCA) receptors. Annu. Rev. Pharmacol. Toxicol. 54, 407-434. doi: 10.1146/annurevpharmtox-011613-135945

Olivares, M., Neyrinck, A. M., Potgens, S. A., Beaumont, M., Salazar, N., Cani, P. D., et al. (2018a). The DPP-4 inhibitor vildagliptin impacts the gut microbiota and prevents disruption of intestinal homeostasis induced by a Western diet in mice. Diabetologia 61, 1838-1848. doi: 10.1007/s00125-018-4647-6

Olivares, M., Schuppel, V., Hassan, A. M., Beaumont, M., Neyrinck, A. M., Bindels, L. B., et al. (2018b). The potential role of the dipeptidyl peptidase-4-like activity from the gut microbiota on the host health. Front. Microbiol. 9:1900. doi: 10.3389/fmicb.2018.03313

Owyang, C., and Logsdon, C. D. (2004). New insights into neurohormonal regulation of pancreatic secretion. Gastroenterology 127, 957-969. doi: 10.1053/ j.gastro.2004.05.002

Paratore, S., Ciotti, M. T., Basille, M., Vaudry, D., Gentile, A., Parenti, R., et al. (2011). Gastric inhibitory polypeptide and its receptor are expressed in the central nervous system and support neuronal survival. Cent. Nerv. Syst. Agents Med. Chem. 11, 210-222. doi: 10.2174/187152411798047771

Pathak, P., Liu, H., Boehme, S., Xie, C., Krausz, K. W., Gonzalez, F., et al. (2017). Farnesoid X receptor induces Takeda G-protein receptor 5 cross-talk to regulate bile acid synthesis and hepatic metabolism. J. Biol. Chem. 292, 11055-11069. doi: 10.1074/jbc.M117.784322

Pedersen, H. K., Gudmundsdottir, V., Nielsen, H. B., Hyotylainen, T., Nielsen, T., Jensen, B. A., et al. (2016). Human gut microbes impact host serum metabolome and insulin sensitivity. Nature 535, 376-381. doi: 10.1038/nature18646

Psichas, A., Sleeth, M. L., Murphy, K. G., Brooks, L., Bewick, G. A., Hanyaloglu, A. C., et al. (2015). The short chain fatty acid propionate stimulates GLP-1 and PYY secretion via free fatty acid receptor 2 in rodents. Int. J. Obes. 39, 424-429. doi: 10.1038/ijo.2014.153

Raghupathi, R., Duffield, M. D., Zelkas, L., Meedeniya, A., Brookes, S. J., Sia, T. C., et al. (2013). Identification of unique release kinetics of serotonin from guinea-pig and human enterochromaffin cells. J. Physiol. 591, 5959-5975. doi: 10.1113/jphysiol.2013.259796

Raghupathi, R., Jessup, C. F., Lumsden, A. L., and Keating, D. J. (2016). Fusion pore size limits 5-HT release from single enterochromaffin cell vesicles. J. Cell. Physiol. 231, 1593-1600. doi: 10.1002/jcp.25256

Raybould, H. E. (1991). Capsaicin-sensitive vagal afferents and CCK in inhibition of gastric motor function induced by intestinal nutrients. Peptides 12, 1279-1283. doi: 10.1016/0196-9781(91)90207-6

Raybould, H. E., and Tache, Y. (1988). Cholecystokinin inhibits gastric motility and emptying via a capsaicin-sensitive vagal pathway in rats. Am. J. Physiol. 255, G242-G246. doi: 10.1152/ajpgi.1988.255.2.G242

Reigstad, C. S., Salmonson, C. E., Rainey, J. F. III, Szurszewski, J. H., Linden, D. R., Sonnenburg, J. L., et al. (2015). Gut microbes promote colonic serotonin production through an effect of short-chain fatty acids on enterochromaffin cells. FASEB J. 29, 1395-1403. doi: 10.1096/fj.14-259598

Ridaura, V. K., Faith, J. J., Rey, F. E., Cheng, J., Duncan, A. E., Kau, A. L., et al. (2013). Gut microbiota from twins discordant for obesity modulate metabolism in mice. Science 341, 1241214. doi: 10.1126/science. 1241214 
Ritter, R. C. (2004). Gastrointestinal mechanisms of satiation for food. Physiol. Behav. 81, 249-273. doi: 10.1016/j.physbeh.2004.02.012

Roager, H. M., Hansen, L. B. S., Bahl, M. I., Frandsen, H. L., Carvalho, V., Gøbel, R. J., et al. (2016). Colonic transit time is related to bacterial metabolism and mucosal turnover in the gut. Nat. Microbiol. 1:16093. doi: 10.1038/nmicrobiol. 2016.93

Rodrigues, R. R., Greer, R. L., Dong, X., DSouza, K. N., Gurung, M., Wu, J. Y., et al. (2017). Antibiotic-induced alterations in gut microbiota are associated with changes in glucose metabolism in healthy mice. Front. Microbiol. 8:2306. doi: 10.3389/fmicb.2017.02306

Rogers, G. B., Keating, D. J., Young, R. L., Wong, M. L., Licinio, J., and Wesselingh, S. (2016). From gut dysbiosis to altered brain function and mental illness: mechanisms and pathways. Mol. Psychiatry 21, 738-748. doi: 10.1038/ mp.2016.50

Rogers, R. C., and Hermann, G. E. (2008). Mechanisms of action of CCK to activate central vagal afferent terminals. Peptides 29, 1716-1725. doi: 10.1016/j.peptides. 2008.06.023

Scarpellini, E., Ianiro, G., Attili, F., Bassanelli, C., De Santis, A., and Gasbarrini, A. (2015). The human gut microbiota and virome: potential therapeutic implications. Dig. Liver Dis. 47, 1007-1012. doi: 10.1016/j.dld.2015.07.008

Seeley, R. J., Chambers, A. P., and Sandoval, D. A. (2015). The role of gut adaptation in the potent effects of multiple bariatric surgeries on obesity and diabetes. Cell Metab. 21, 369-378. doi: 10.1016/j.cmet.2015.01.001

Sileikiene, V., Mosenthin, R., Bauer, E., Piepho, H. P., Tafaj, M., Kruszewska, D., et al. (2008). Effect of ileal infusion of short-chain fatty acids on pancreatic prandial secretion and gastrointestinal hormones in pigs. Pancreas 37, 196-202. doi: 10.1097/MPA.0b013e31816386f4

Spencer, N. J., and Keating, D. J. (2016). Is there a role for endogenous 5-HT in gastrointestinal motility? how recent studies have changed our understanding. Adv. Exp. Med. Biol. 891, 113-122. doi: 10.1007/978-3-319-27592-5_11

Spencer, N. J., Nicholas, S. J., Robinson, L., Kyloh, M., Flack, N., Brookes, S. J., et al. (2011). Mechanisms underlying distension-evoked peristalsis in guinea pig distal colon: is there a role for enterochromaffin cells? Am. J. Physiol. Gastrointestinal Liver Physiol. 301, G519-G527. doi: 10.1152/ajpgi.00101.2011

Spencer, N. J., Sia, T. C., Brookes, S. J., Costa, M., and Keating, D. J. (2015). CrossTalk opposing view: 5-HT is not necessary for peristalsis. J. Physiol. 593, 3229-3231. doi: 10.1113/JP270183

Suarez-Zamorano, N., Fabbiano, S., Chevalier, C., Stojanovic, O., Colin, D. J., Stevanovic, A., et al. (2015). Microbiota depletion promotes browning of white adipose tissue and reduces obesity. Nat. Med. 21, 1497-1501. doi: 10.1038/nm. 3994

Suez, J., Korem, T., Zeevi, D., Zilberman-Schapira, G., Thaiss, C. A., Maza, O., et al. (2014). Artificial sweeteners induce glucose intolerance by altering the gut microbiota. Nature 514, 181-186. doi: 10.1038/nature13793

Suez, J., Korem, T., Zilberman-Schapira, G., Segal, E., and Elinav, E. (2015). Noncaloric artificial sweeteners and the microbiome: findings and challenges. Gut Microbes 6, 149-155. doi: 10.1080/19490976.2015.1017700

Sumara, G., Sumara, O., Kim, J. K., and Karsenty, G. (2012). Gut-derived serotonin is a multifunctional determinant to fasting adaptation. Cell Metab. 16, 588-600. doi: 10.1016/j.cmet.2012.09.014

Sun, E. W., de Fontgalland, D., Rabbitt, P., Hollington, P., Sposato, L., Due, S. L., et al. (2017). Mechanisms controlling glucose-induced GLP-1 secretion in human small intestine. Diabetes Metab. Res. Rev. 66, 2144-2149. doi: 10.2337/ db17-0058

Takahashi, T., Yano, M., Minami, J., Haraguchi, T., Koga, N., Higashi, K., et al. (2002). Sarpogrelate hydrochloride, a serotonin2A receptor antagonist, reduces albuminuria in diabetic patients with early-stage diabetic nephropathy. Diabetes Res. Clin. Pract. 58, 123-129. doi: 10.1016/S0168-8227(02)00105-5

Takeuchi, O., and Akira, S. (2002). Genetic approaches to the study of toll-like receptor function. Microbes Infect. 4, 887-895. doi: 10.1016/S1286-4579(02) 01615-5

Thondam, S. K., Daousi, C., Wilding, J. P., Holst, J. J., Ameen, G. I., Yang, C., et al. (2017). Glucose-dependent insulinotropic polypeptide promotes lipid deposition in subcutaneous adipocytes in obese type 2 diabetes patients: a maladaptive response. Am. J. Physiol. Endocrinol. Metab. 312, E224-E233. doi: 10.1152/ajpendo.00347.2016

Thorn, P., Zorec, R., Rettig, J., and Keating, D. J. (2016). Exocytosis in nonneuronal cells. J. Neurochem. 137, 849-859. doi: 10.1111/jnc.13602
Tolhurst, G., Heffron, H., Lam, Y. S., Parker, H. E., Habib, A. M., Diakogiannaki, E., et al. (2012). Short-chain fatty acids stimulate glucagon-like peptide-1 secretion via the G-protein-coupled receptor FFAR2. Diabetes Metab. Res. Rev. 61, 364-371. doi: 10.2337/db11-1019

Topping, D. L., and Clifton, P. M. (2001). Short-chain fatty acids and human colonic function: roles of resistant starch and nonstarch polysaccharides. Physiol. Rev. 81, 1031-1064. doi: 10.1152/physrev.2001.81.3.1031

Tremaroli, V., and Backhed, F. (2012). Functional interactions between the gut microbiota and host metabolism. Nature 489, 242-249. doi: 10.1038/ nature 11552

Turnbaugh, P. J., and Gordon, J. I. (2009). The core gut microbiome, energy balance and obesity. J. Physiol. 587, 4153-4158. doi: 10.1113/jphysiol.2009. 174136

Turnbaugh, P. J., Hamady, M., Yatsunenko, T., Cantarel, B. L., Duncan, A., Ley, R. E., et al. (2009). A core gut microbiome in obese and lean twins. Nature 457, 480-484. doi: 10.1038/nature07540

Turnbaugh, P. J., Ley, R. E., Mahowald, M. A., Magrini, V., Mardis, E. R., and Gordon, J. I. (2006). An obesity-associated gut microbiome with increased capacity for energy harvest. Nature 444, 1027-1031. doi: 10.1038/nature05414

Vandeputte, D., Falony, G., Vieira-Silva, S., Tito, R. Y., Joossens, M., and Raes, J. (2016). Stool consistency is strongly associated with gut microbiota richness and composition, enterotypes and bacterial growth rates. Gut 65, 57-62. doi: 10.1136/gutjnl-2015-309618

Vangay, P., Johnson, A. J., Ward, T. L., Al-Ghalith, G. A., Shields-Cutler, R. R., Hillmann, B. M., et al. (2018). US immigration westernizes the human gut microbiome. Cell 175, 962.e10-972.e10. doi: 10.1016/j.cell.2018. 10.029

Vilsboll, T., Krarup, T., Madsbad, S., and Holst, J. J. (2002). Defective amplification of the late phase insulin response to glucose by GIP in obese type II diabetic patients. Diabetologia 45, 1111-1119. doi: 10.1007/s00125-0020878-6

Vincent, A. D., Wang, X. Y., Parsons, S. P., Khan, W. I., and Huizinga, J. D. (2018). Abnormal absorptive colonic motor activity in germ free mice is rectified by butyrate, an effect possibly mediated by mucosal serotonin. Am. J. Physiol. Gastrointest. Liver Physiol. 315, G896-G907. doi: 10.1152/ajpgi.00237.2017

Vrieze, A., Out, C., Fuentes, S., Jonker, L., Reuling, I., Kootte, R. S., et al. (2014). Impact of oral vancomycin on gut microbiota, bile acid metabolism, and insulin sensitivity. J. Hepatol. 60, 824-831. doi: 10.1016/j.jhep.2013.11.034

Vrieze, A., Van Nood, E., Holleman, F., Salojarvi, J., Kootte, R. S., Bartelsman, J. F., et al. (2012). Transfer of intestinal microbiota from lean donors increases insulin sensitivity in individuals with metabolic syndrome. Gastroenterology 143, 913.e7-916.e7. doi: 10.1053/j.gastro.2012.06.031

Waldecker, M., Kautenburger, T., Daumann, H., Busch, C., and Schrenk, D. (2008). Inhibition of histone-deacetylase activity by short-chain fatty acids and some polyphenol metabolites formed in the colon. J. Nutr. Biochem. 19, 587-593. doi: 10.1016/j.jnutbio.2007.08.002

Watanabe, H., Saito, R., Nakano, T., Takahashi, H., Takahashi, Y., Sumiyoshi, K., et al. (2014). Effect of peripheral 5-HT on glucose and lipid metabolism in wether sheep. PLoS One 9:e88058. doi: 10.1371/journal.pone.0088058

Widenmaier, S. B., Ao, Z., Kim, S. J., Warnock, G., and McIntosh, C. H. (2009). Suppression of p38 MAPK and JNK via Akt-mediated inhibition of apoptosis signal-regulating kinase 1 constitutes a core component of the beta-cell prosurvival effects of glucose-dependent insulinotropic polypeptide. J. Biol. Chem. 284, 30372-30382. doi: 10.1074/jbc.M109.060178

Wu, H., Esteve, E., Tremaroli, V., Khan, M. T., Caesar, R., Mannerås-Holm, L., et al. (2017). Metformin alters the gut microbiome of individuals with treatmentnaive type 2 diabetes, contributing to the therapeutic effects of the drug. Nat. Med. 22, 850-858. doi: 10.1038/nm.4345

Yano, J. M., Yu, K., Donaldson, G. P., Shastri, G. G., Ann, P., Ma, L., et al. (2015). Indigenous bacteria from the gut microbiota regulate host serotonin biosynthesis. Cell 161, 264-276. doi: 10.1016/j.cell.2015. 02.047

Yip, R. G., Boylan, M. O., Kieffer, T. J., and Wolfe, M. M. (1998). Functional GIP receptors are present on adipocytes. Endocrinology 139, 4004-4007. doi: 10.1210/endo.139.9.6288

Young, R. L., Lumsden, A. L., and Keating, D. J. (2015). Gut serotonin is a regulator of obesity and metabolism. Gastroenterology 149, 253-255. doi: 10. 1053/j.gastro.2015.05.020 
Young, R. L., Lumsden, A. L., Martin, A. M., Schober, G., Pezos, N., Thazhath, S. S., et al. (2018). Augmented capacity for peripheral serotonin release in human obesity. Int. J. Obes. 42, 1880-1889. doi: 10.1038/s41366-0180047-8

Zarrinpar, A., Chaix, A., Xu, Z. Z., Chang, M. W., Marotz, C. A., Saghatelian, A., et al. (2018). Antibiotic-induced microbiome depletion alters metabolic homeostasis by affecting gut signaling and colonic metabolism. Nat. Commun. 9:2872. doi: 10.1038/s41467-018-05336-9

Zelkas, L., Raghupathi, R., Lumsden, A. L., Martin, A. M., Sun, E., Spencer, N. J., et al. (2015). Serotonin-secreting enteroendocrine cells respond via diverse mechanisms to acute and chronic changes in glucose availability. Nutr. Metab. 12:55. doi: 10.1186/s12986-015-0051-0
Conflict of Interest Statement: The authors declare that the research was conducted in the absence of any commercial or financial relationships that could be construed as a potential conflict of interest.

The handling Editor declared a past collaboration with one of the authors DK.

Copyright (c) 2019 Martin, Sun, Rogers and Keating. This is an open-access article distributed under the terms of the Creative Commons Attribution License (CC BY). The use, distribution or reproduction in other forums is permitted, provided the original author(s) and the copyright owner(s) are credited and that the original publication in this journal is cited, in accordance with accepted academic practice. No use, distribution or reproduction is permitted which does not comply with these terms. 